\title{
Prehospital Systolic Hypertension and Outcomes in Patients with Spontaneous Intracerebral Hemorrhage
}

\author{
Stacy Hatcher ${ }^{1}$, Connie Chen ${ }^{2}$, Prasanthi Govindarajan ${ }^{3}$ \\ 1. Department of Surgery, University of California San Francisco 2. Internal Medicine, Stanford \\ Healthcare 3. Emergency Medicine, Stanford Hospital, Palo Alto, USA
}

$\square$ Corresponding author: Stacy Hatcher, stacy.hatcher@ucsf.edu Disclosures can be found in Additional Information at the end of the article

\section{Abstract}

\section{Background}

It is well known that hematoma volume and expansion is associated with poor outcomes in patients with spontaneous intracerebral hemorrhage (sICH). The factors associated with hematoma volume and possible expansion include the use of anticoagulant medications, autoimmune or bacterial diseases that reduce platelet production, and genetic defects of Von Willebrand factor causing inhibition or reduction of platelet aggregation.

However, little is known about the role of elevated systolic blood pressure (SBP) on hematoma volume and its ultimate role on sICH when identified in the prehospital setting. Our objectives were to determine the prevalence of elevated SBP among diagnosed sICH patients transported by emergency medical services (EMS), and to explore possible associations between prehospital elevated SBP and hematoma volume.

\section{Methods}

This is a hypothesis-generating study for which we used a retrospective observational design. The subjects included 243 adult patients who were seen and treated for sICH in an emergency department serving a county hospital in a large metropolitan city. Elevated SBP in the setting of sICH was defined as $\geqslant 140 \mathrm{~mm} \mathrm{Hg}$. A univariate analysis was performed to investigate associations between patient demographics, elevated SBP, and SICH characteristics with the pre-determined outcome of hematoma volume. We then performed a multivariable logistic regression model to determine if elevated prehospital SBP remained associated with hematoma volume.

Received 09/14/2016 Review began 09/28/2016 Review ended 01/18/2017 Published 01/26/2017

\section{(c) Copyright 2017}

Hatcher et al. This is an open access article distributed under the terms of the Creative Commons Attribution License CC-BY 3.0., which permits unrestricted use, distribution, and reproduction in any medium, provided the original author and source are credited.

\section{Results}

The number of subjects with a hospital-based diagnosis of sICH was 243. Of those, 193 (79\%) were transported by an ambulance. Among those transported by ambulance, 180 (93\%) had a documented prehospital SBP; out of those patients with a documented SBP, 173 (96\%) showed an elevated SBP of $\geqslant 140 \mathrm{~mm} \mathrm{Hg}$, and 82 (46\%) had a hematoma volume of $\geqslant 30 \mathrm{~mL}$.

Our univariate analysis showed that sICH patients with an elevated prehospital SBP of $\geqslant 140$ $\mathrm{mm} \mathrm{Hg}$ were associated with hematoma volume. The multivariable regression model showed that elevated prehospital SBP ( $\geqslant 140 \mathrm{~mm} \mathrm{Hg}$ ) was associated with larger hematoma volumes (odds ratio (OR) 3.86 95\% confidence interval (CI) 1.02-4.60). 


\section{Conclusions}

Prehospital elevated SBP is associated with larger hematoma volume in patients with sICH. Future studies should confirm these findings in a larger cohort of patients.

Categories: Emergency Medicine, Neurology, Public Health

Keywords: stroke, emergency medical services, hypertension, ct, intracerebral hemorrhage, prehospital care, prehospital life support

\section{Introduction}

Spontaneous nontraumatic intracerebral hemorrhage (sICH) is a neurovascular emergency and constitutes about $10 \%$ of all strokes [1]. It is also a leading cause of disability and mortality; approximately $40 \%$ of sICH patients die within 30 days [2]. Prognostic factors associated with hematoma volume and possible expansion such as the use of anticoagulant medications, autoimmune or bacterial diseases that reduce platelet production, and genetic defects of Von Willebrand factor causing inhibition or reduction of platelet aggregation have been studied over the years and have shown to be associated with poor outcomes [3-4]. Mortality rates, however, have not changed significantly. Control of hematoma expansion may hold the most promise as a therapeutic target. While traditional models indicate direct injury to neurons from the hematoma as a contributing factor of poor patient outcomes, the recent focus has shifted in favor of factors that might aggravate secondary brain injury such as early hematoma expansion, edema, and neurohemoinflammation.

Hematoma expansion is known to occur in the first hour after a baseline CT scan in a third of patients with sICH and is associated with significant neurodeterioration, a predictor of morbidity and mortality [5-7]. A literature review conducted by Morgenstern, et al. corroborated similar findings in which elevated SBP (>140 mm Hg) within 12 hours post sICH was associated with significantly higher mortality and morbidity [8].

Inhospital association between elevated SBP and neurodeterioration has been studied, [7,9], and analyses conducted by Qureshi, et al. have showed an association between mortality and initial mean arterial pressure (MAP), (MAP=Diastolic Blood Pressure + 1/3 Pulse Pressure), but did not show a significant association between elevated initial MAP and early neurologic deterioration [6]. Consequently, elevated prehospital SBP and its association with hematoma volume, disability and mortality are yet to be clearly determined.

The multicenter observational pilot study 'Antihypertensive Treatment of Acute Cerebral Hemorrhage-I' (ATACH I), and the 'Intensive Blood Pressure Reduction in Acute Cerebral Haemorrhage-I' (INTERACT I) pilot trial showed that early and aggressive lowering of blood pressure was feasible and reasonably safe, but ultimately did not result in any appreciable decrease in the rate of death, severe disability, or hematoma growth [10-11]. Analysis of the modified Rankin scale data collected in the INTERACT II trial did however indicate better functional outcomes when aggressive SBP lowering was instituted compared to the control group [12-14].

These trials formed the basis for the randomized Phase III clinical trial ATACH II, which sought to determine the efficacy of early and intensive blood pressure lowering treatment administered within three hours of sICH onset and continued for the next 24 hours. Similar to the ATACH I and INTERACT I and II studies, recently published results have shown no appreciable decrease in the rate of death, or disability [10-12, 15-16].

We aim to identify the prevalence of prehospital elevated SBP as defined by $\geqslant 140 \mathrm{~mm} \mathrm{Hg}$ and 
determine if an association exists between elevated prehospital SBP and hematoma volume. This study, while exploratory in nature, may shed light on the contribution of prehospital factors in ultra-early management of sICH and its associated outcomes, as well as expand the horizon of possible factors that could contribute to improved outcomes in sICH patients.

\section{Materials And Methods}

\section{Study design and setting}

This is a three-year retrospective observational cohort study of patients admitted through a single emergency department with a new diagnosis of sICH confirmed via computed tomography (CT) scan in the hospital. Subject enrollment and data acquisition are described previously [17-18]. All aspects of this study were approved by the Committee on Human Research of the University of California, San Francisco. Informed consent was waived because of minimal patient risk and because only deidentified data were included.

\section{Selection of participants}

We included all ambulance-transported subjects with a final inhospital diagnosis of sICH. Interhospital transfers were excluded.

\section{Methods of measurement, data collection and processing}

The patient demographic variables used for analysis included date of birth, gender, ethnicity, and race. The baseline variables included SBP recording and pre-sICH functional status and baseline characteristics, including modified Rankin Score (mRS) and use of anticoagulants. Post-sICH characteristics recorded include hematoma volume, location of the hemorrhage, and presence of intraventricular hemorrhage. The patient outcomes during and following hospitalization were available for analysis.

\section{Study definition}

The hematoma volume and outcomes associated with prehospital SBP of $\geqslant 140 \mathrm{~mm}$ Hg were analyzed. Although data on other prehospital vital signs were available, we chose to focus solely on SBP and Glasgow Coma Scale (GCS). This selective approach was done to prevent inaccurate risk estimates resulting from the use of too many independent variables in a model with a small sample size.

\section{Outcome measures}

The primary outcome measure was hematoma volume upon initial CT at the emergency department (ED) (Table 2). The secondary outcome measure was prehospital neurologic deterioration as defined by $\mathrm{a} \geqslant 2$ point decrease in GCS between EMS and ED evaluation [17]. Both radiological and clinical outcomes were temporally related to prehospital transport.

\section{Primary data analysis}

The patients were initially categorized by hematoma size ( $\geqslant 30 \mathrm{~mL}$ and $<30 \mathrm{~mL}$ ) [17]. The demographics were described using frequencies and percentages for dichotomous and categorical variables. We studied the association between prehospital SBP and hematoma size using a univariate analysis. Associations between key adjustment variables such as subject demographics, baseline functional status, and sICH characteristics and outcomes were also explored (Table 1). The patient demographics and ICH characteristic variables for the regression model were chosen based on both face validity and associations observed in previous research [7-12, 14, 17-23]. 


\section{Cureus}

In our multivariate model we sought to determine if an independent association existed between components of prehospital SBP and hematoma size at initial CT when controlling for demographic characteristics, baseline functional status of the subject, and sICH characteristics. A p-value of 0.05 was considered significant. Statistical analysis was performed using STATA Version 10.0 (Statacorp, TX, USA).

\section{Results}

The subjects included 243 adult patients who were seen and treated for sICH in an emergency department serving a county hospital in a large metropolitan city. Out of those 243 subjects, 193 were transported by ambulance and had a mean age of 66 years (SD+/-14.5). Nintey-eight (51\%) were male. A total of 180 (93\%) patients had a documented prehospital SBP, out of which 173 (90\%) showed an elevated SBP of $\geqslant 140 \mathrm{~mm} \mathrm{Hg}$, and 82 (43\%) had a hematoma volume of $\geqslant 30 \mathrm{~mL}$. The mean hematoma volume according to the CT scan on admission was 41 $\mathrm{mL}(\mathrm{SD}=47 \mathrm{~mL})$ (Table 1$)$.

The univariate analysis (Table 2) showed that elevated prehospital SBP $\geqslant 140 \mathrm{~mm} \mathrm{Hg}$ was associated with a hematoma volume of $\geqslant 30 \mathrm{~mL}$. The changes reported in hematoma volume were calculated based on volume at initial CT and CT 24 hours later (OR $4.2195 \%$ CI 1.17-15.13), presence of hematoma volumes of $\geqslant 30 \mathrm{~mL}$ at initial CT scan (OR $4.0095 \%$ CI 2.187.28), and a negative change in functional status leading to severe disability as measured by mRS score of 4-5. Severe disability was noted at 30 days compared to an initial patient evaluation of moderate disability as measured by mRS score of three (OR 4.14 95\% CI 1.5211.57). The factors associated with higher 30-day mortality include presence of intraventricular hemorrhage (IVH) (OR $3.3695 \%$ CI 1.80-6.27), increase in hematoma volume of $\geqslant 0.03 \mathrm{~mL}$ (OR 4.20 95\% CI 1.17-15.13), and lower prehospital GCS scores of 4-12 (OR 3.40 95\% CI 1.89-6.13) and <4 (OR 14.01 95\% CI 3.2-62.17).

In the multivariable regression model, elevated prehospital SBP ( $\geqslant 140 \mathrm{~mm} \mathrm{Hg}$ ) was associated with a trend towards larger hematoma volume (OR 3.86 95\% CI 1.02- 4.60). No statistically significant associations were noted between prehospital SBP and 30-day mortality (OR 0.10 95\% CI 0.2-4.97), severe disability (OR 3.64 95\% CI 1.01-13.06), and prehospital neurodeterioration (OR 1.22 95\% CI 0.39-5.20) (Table 3).

\begin{tabular}{|c|c|c|c|c|}
\hline \multirow[t]{2}{*}{ Characteristics } & \multirow{2}{*}{$\begin{array}{l}\text { All Subjects } \\
n=193(\%)\end{array}$} & \multicolumn{2}{|c|}{ Outcome at 30 days } & \multirow[t]{2}{*}{ p-value } \\
\hline & & Alive & Deceased & \\
\hline & & $\mathrm{n}=97$ & $n=96$ & \\
\hline \multicolumn{5}{|l|}{ Age (years) } \\
\hline Mean (SD, Min-Max) & $66(14.5,25-94)$ & $65.4(14.5)$ & $67.4(14.5)$ & 0.03 \\
\hline \multicolumn{5}{|l|}{ Sex } \\
\hline No. (\%) Male & 98 (51\%) & $52(53 \%)$ & $38(49 \%)$ & 0.22 \\
\hline \multicolumn{5}{|l|}{ Race/ Ethnicity } \\
\hline White & 68 (34\%) & 34 (34\%) & $35(38 \%)$ & 0.28 \\
\hline Black & $36(19 \%)$ & $21(23 \%)$ & $15(15 \%)$ & 0.84 \\
\hline Asian & $82(43 \%)$ & $40(41 \%)$ & $42(44 \%)$ & 0.34 \\
\hline
\end{tabular}




\section{Cureus}

Other non-white

Pre-Rankin $\geq 4$

Prehospital GCS

Mild (13-15)

Moderate (4-12)

Severe $(<4)$

First GCS in ED

Mild (13-15)

Moderate (4-12)

Severe $(<4)$

Neurodeterioration during EMS transport

Prehospital systolic blood pressure

$$
\text { Mean (SD) }
$$

Hematoma volume $(\mathrm{mL})$

Mean (SD)

Hematoma volume $<30 \mathrm{~cm}^{3}$

Hematoma volume $\geq 30 \mathrm{~cm}^{3}$

Intraventricular hemorrhage present

Infratentorial bleed
$5(3 \%)$

$9(5 \%)$

$2(2 \%)$

$3(3 \%)$

0.44

$0(0 \%)$

$9(9 \%)$

$<0.01$

$81(44 \%)$

$58(68 \%)$

$13(19 \%)$

$<0.01$

$43(23 \%)$

$14(30 \%)$

$29(59 \%)$

$<0.01$

$62(33 \%)$

$3(2 \%)$

$59(23 \%)$

$<0.01$

$81(42 \%)$

$67(72 \%)$

$14(14 \%)$

$<0.01$

$86(45 \%)$

$24(26 \%)$

$62(62 \%)$

$<0.01$

$24(13 \%)$

$2(2 \%)$

$22(25 \%)$

$<0.01$

45 (24\%)

$18(20 \%)$

$27(27 \%)$

$<0.01$

185 (41)

179 (4)

190 (4)

0.05

41 (47)

17 (2)

$62(5)$

$<0.01$

109 (57\%)

$68(75 \%)$

$41(41 \%)$

$<0.01$

$82(43 \%)$

$23(25 \%)$

$59(59 \%)$

$<0.01$

123 (64\%)

$46(50 \%)$

77 (77\%)

$<0.01$

$38(20 \%)$

$18(19 \%)$

$20(20 \%)$

0.68

\section{TABLE 1: Background Characteristics}

Note: SD-Standard Deviation; Some analyses are based on fewer observations than the total $\mathrm{n}$ because of missing data. Neurodeterioration is defined as $a \geq 2$ point decrease from EMS to ED. 


\section{Cureus}

\begin{tabular}{|c|c|c|c|c|c|c|}
\hline \multirow[b]{2}{*}{ Predictor } & \multicolumn{3}{|c|}{ Univariate Analysis } & \multicolumn{3}{|c|}{ Muitıvariate Analysıs } \\
\hline & OR & $95 \% \mathrm{Cl}$ & $p$-value & OR & $95 \% \mathrm{Cl}$ & $\mathrm{p}$-value \\
\hline Age $>80$ years & 1.35 & $0.68-2.68$ & 0.39 & 1.11 & $0.53-2.37$ & 0.78 \\
\hline Female & 1.09 & 0.61-1.94 & 0.77 & 1.11 & $0.59-2.06$ & 0.75 \\
\hline Asian & 1.02 & 0.57-1.84 & 0.93 & 0.63 & $0.32-1.24$ & 0.18 \\
\hline Black & 0.37 & $0.16-0.84$ & 0.02 & 0.32 & $0.13-0.83$ & 0.02 \\
\hline Other non-white & 2.03 & $0.33-12.47$ & 0.45 & 1.02 & $0.13-8.08$ & 0.99 \\
\hline Pre-event mRS $\geq 4$ & 0.66 & $0.16-2.69$ & 0.55 & 0.54 & $0.10-2.82$ & 0.46 \\
\hline Infratentorial location & 0.07 & $0.02-0.27$ & $<0.01$ & - & - & - \\
\hline IVH present & 1.80 & $0.97-3.34$ & 0.06 & - & - & - \\
\hline Prehospital GCS (4-12) & 2.00 & 1.11-3.62 & 0.02 & 2.22 & $1.11-4.46$ & 0.03 \\
\hline Prehospital GCS <4 & 1.38 & $0.58-3.26$ & 0.46 & 2.22 & $0.85-5.79$ & 0.10 \\
\hline Prehospital SBP > 140 mmHg & 4.21 & $1.17-15.13$ & 0.03 & 3.86 & $1.02-4.60$ & 0.05 \\
\hline
\end{tabular}

\section{TABLE 2: Logistic Regression Model on Hematoma Volume}

GCS-Glasgow Coma Scale, Cl-Confidence Interval, OR-Odds Ratio, mRS-Modified Rankin Score, ICH Volume-Intracranial Hemorrhage Volume, IVH-Intraventricular Hemorrhage; Outcomes: hematoma volume (dichotomize at $30 \mathrm{~cm}^{\wedge} 3$ ), Prehospital neurodeterioration (decrease in GCS by $\geq 2$ points between EMS and ED arrival), Disability (change from $<4$ to $\geq 4$ on $\mathrm{mRS}$ ), Primary predictor variable: systolic blood pressure $\geq 140 \mathrm{~mm} \mathrm{Hg}$, Controls: age $\geq 80 \mathrm{y}$, gender, race, pre-Rankin, location-infratentorial, volume $\geq 30$, and presence of IVH. 


\section{Cureus}

\section{Death}

\begin{tabular}{|c|c|c|c|c|c|c|}
\hline \multirow[b]{2}{*}{ Predictor } & \multicolumn{3}{|c|}{ Univariate Analysis } & \multicolumn{3}{|c|}{ Multivariate Analysis } \\
\hline & OR & $95 \% \mathrm{Cl}$ & p-value & OR & $95 \% \mathrm{Cl}$ & p-value \\
\hline Age $>80$ years & 0.84 & $0.42-1.67$ & 0.63 & 0.66 & $0.27-\quad 1.62$ & 0.36 \\
\hline Female & 1.16 & $0.66-2.03$ & 0.61 & 0.10 & $0.47-\quad 2.13$ & 0.10 \\
\hline Asian & 1.16 & $0.66-2.03$ & 0.62 & 0.90 & $0.39-2.12$ & 0.82 \\
\hline Black & 0.67 & $0.32-1.39$ & 0.29 & 1.09 & $0.35-3.39$ & 0.88 \\
\hline Other non-white & 1.53 & $0.25-9.42$ & 0.65 & 0.78 & $0.09-6.53$ & 0.82 \\
\hline Pre-event $\mathrm{mRS} \geq 4$ & - & Co-linear & - & - & - & - \\
\hline $\mathrm{ICH}$ volume $>30 \mathrm{~mL}$ & 3.98 & $2.18-7.28$ & $<0.01$ & 4.84 & $1.97-11.90$ & $<0.01$ \\
\hline Infratentorial location & 1.01 & $0.50-2.06$ & 0.97 & 1.61 & $0.49-5.25$ & 0.43 \\
\hline IVH present & 3.36 & $1.80-6.27$ & $<0.01$ & 2.90 & $1.30-6.49$ & 0.01 \\
\hline Prehospital GCS 4-12 & 3.40 & $1.89-6.13$ & $<0.01$ & 6.27 & 2.82- 13.92 & $<0.01$ \\
\hline Prehospital GCS <4 & 14.01 & $3.2-62.17$ & $<0.01$ & 30.86 & $5.86-162.49$ & $<0.01$ \\
\hline Prehospital SBP > $140 \mathrm{mmHg}$ & 0.49 & $0.60-0.40$ & 0.34 & 0.10 & $0.20-4.97$ & 0.10 \\
\hline
\end{tabular}

\section{TABLE 3: Logistic Regression Model for Death}

GCS-Glasgow Coma Scale, Cl-Confidence Interval, OR-Odds Ratio, mRS-Modified Rankin Score, ICH-Intracranial Hemorrhage, IVHIntraventricular Hemorrhage; Outcome: mortality (yes/no), Primary predictor variable: systolic blood pressure $\geq 140 \mathrm{~mm} \mathrm{Hg}$,

Controls: age $\geq 80 y$, gender, race, pre-rankin, presenting GCS $\geq 3,4-12, \geq 13$, location-infratentorial, volume $\geq 30$ and presence of IVH.

\section{Discussion}

A national study noted that initial SBP in patients presenting to the ED was elevated at $\geqslant 140$ $\mathrm{mm} \mathrm{Hg}$ in $69 \%$ of stroke patients [9]. In our sICH-only cohort we noted a higher (91\%) proportion of prehospital systolic hypertension. The higher proportion may be due to our inclusion of only sICH patients versus a cohort including all stroke types.

Further studies on this topic have shown mixed results. The INTERACT I pilot showed hematoma attenuation over 72 hours in the treatment group (aggressive blood pressure (BP) lowering) within six hours of sICH onset [11]. However, the final results of the INTERACT II trial showed no significant difference in hematoma growth between treatment and control groups. Analysis of INTERACT II mRS scores did however suggest that intensive treatment improved functional outcomes [16]. A post hoc analysis by Jauch EC, et al. similarly did not show any associations between hemodynamic parameters and hematoma growth but states that this association still remains unclear and warrants further research [13].

An interesting study by Fan, et al. (2015) showed that compared to inhospital blood pressure readings, increased on-scene systolic, diastolic, and mean arterial pressures were all 
independently and more strongly associated with increasing neurologic deterioration as defined by $\geqslant 2$ decrease in GCS within 24 hours after ED admission [19].

Differing results between other studies described could be attributed to differences in demographics of the patient population and study settings. The main limitation for this study was our small sICH cohort size as evidenced by wide confidence intervals.

ICH is seldom diagnosed in the prehospital setting due to lack of imaging modalities. CT equipped ambulances are available in parts of Europe and the United States and may play an increasing role in prehospital stroke care in the future. While we acknowledge these limitations, this is one of the few studies exploring the impact of prehospital SBP on sICH patient outcomes. Based on our findings, we hope to provide valuable information and spur investigation into possible future diagnostic and treatment modalities for sICH patients in the prehospital setting.

\section{Conclusions}

Prehospital elevated SBP is associated with larger hematoma volume on ED arrival in patients with spontaneous intracranial hemorrhage. While these findings are limited by the size of the cohort and unmeasured variables such as prehospital hematoma volume in the early phase of care, future studies using larger sample size, accounting for further prehospital variables, and using a cumulative dose of hypertension (the area calculated under the curve of contiguous MAP values that surpass a set threshold over a certain amount of time) rather than episodic elevations in SBP are likely to shed more light on the association between prehospital SBP and sICH patient outcomes.

\section{Additional Information}

\section{Disclosures}

Human subjects: Consent was obtained by all participants in this study. Committee on Human Research of the University of California San Francisco. issued approval 10-04239. All aspects of this study were approved by the Committee on Human Research of the University of California, San Francisco. . Animal subjects: All authors have confirmed that this study did not involve animal subjects or tissue. Conflicts of interest: In compliance with the ICMJE uniform disclosure form, all authors declare the following: Payment/services info: All authors have declared that no financial support was received from any organization for the submitted work. Financial relationships: All authors have declared that they have no financial relationships at present or within the previous three years with any organizations that might have an interest in the submitted work. Other relationships: All authors have declared that there are no other relationships or activities that could appear to have influenced the submitted work.

\section{Acknowledgements}

The authors would like to acknowledge J. Claude Hemphill III, MD, MAS with the University of California, San Francisco, Department of Neurology and Neurosurgery, San Francisco General Hospital for providing the database used in this study.

\section{References}

1. Lloyd-Jones D, Adams RJ, Brown T, et al.: Heart disease and stroke statistics-2010 update. Circulation. 2010, 121:e46-e215. Accessed: 8 August 2013: http://circ.ahajournals.org/content/121/7/e46. 10.1161/CIRCULATIONAHA.109.192667

2. Rosamond WD, Folsom AR, Chambless LE, et al.: Stroke incidence and survival among middleaged adults: 9-year follow-up of the Atherosclerosis Risk in Communities (ARIC) cohort. 
Stroke. 1999, 30:736-743. 10.1161/01.STR.30.4.736

3. Mayer SA, Brun NC, Begtrup K, et al.: Efficacy and safety of recombinant activated factor VII for acute intracerebral hemorrhage. N Engl J Med. 2008, 358:2127-2137. 10.1056/NEJMoa0707534

4. Davis SM, Broderick J, Hennerici M, et al.: Hematoma growth is a determinant of mortality and poor outcome after intracerebral hemorrhage. Neurology. 2006, 66:1175-1181. 10.1212/01.wnl.0000208408.98482.99

5. Leira R, Dávalos A, Silva Y, et al.: Early neurologic deterioration in intracerebral hemorrhage: predictors and associated factors. Neurology. 2004, 63:461-467.

6. Qureshi AI, Safdar K, Weil EJ, et al.: Predictors of early deterioration and mortality in black Americans with spontaneous intracerebral hemorrhage. Stroke. 1995, 26:1764-1767. 10.1161/01.STR.26.10.1764

7. Arima H, Anderson CS, Wang JG, et al.: Lower treatment blood pressure is associated with greatest reduction in hematoma growth after acute intracerebral hemorrhage. Hypertension. 2010, 56:852-858. 10.1161/HYPERTENSIONAHA.110.154328

8. Morgenstern LB, Hemphill III CJ, Anderson C, et al.: Guidelines for the management of spontaneous intracerebral hemorrhage: a guideline for healthcare professionals from the American Heart Association/American Stroke Association. Stroke. 2010, 41:2108-2129. 10.1161/STR.0b013e3181ec611b

9. Qureshi AI, Ezzeddine MA, Nasar A, et al.: Prevalence of elevated blood pressure in 563,704 adult patients with stroke presenting to the ED in the United States. Am J Emerg Med. 2007, 25:32-38. 10.1016/j.ajem.2006.07.008

10. Antihypertensive treatment of acute cerebral hemorrhage (ATACH) investigators: Antihypertensive treatment of acute cerebral hemorrhage. Crit Care Med. 2010, 38:637-648 . 10.1097/CCM.0b013e3181b9e1a5

11. Anderson CS, Huang Y, Wang JG, et al.: Intensive blood pressure reduction in acute cerebral haemorrhage trial (INTERACT): a randomised pilot trial. Lancet Neurol. 2008, 7:391-399. 10.1016/S1474-4422(08)70069-3

12. Carlberg B, Asplund K, Haag E: The prognostic value of admission blood pressure in patients with acute stroke. Stroke. 1993, 24:1372-1375. 10.1161/01.STR.24.9.1372

13. Jauch EC, Lindsell CJ, Adeoye O, et al.: Lack of evidence for an association between hemodynamic variables and hematoma growth in spontaneous intracerebral hemorrhage. Stroke. 2006, 37:2061-2065. 10.1161/01.STR.0000229878.93759.a2

14. Barton CW, Hemphill JC 3rd: Cumulative dose of hypertension predicts outcome in intracranial hemorrhage better than American Heart Association guidelines. Acad Emerg Med. 2007, 14:695-701. 10.1197/j.aem.2007.03.1358

15. Qureshi AI, Palesch YY: Antihypertensive treatment of acute cerebral hemorrhage (ATACH) II: design, methods, and rationale. Neurocritical Care. 2011, 15:559. 10.1007/s12028-0119538-3

16. Anderson C, Huang Y, Arima H, et al.: Effects of early intensive blood pressure-lowering treatment on the growth of hematoma and perihematomal edema in acute intracerebral hemorrhage: The Intensive Blood Pressure Reduction in Acute Cerebral Hemorrhage Trial (INTERACT). Stroke. 2010, 41:307-312. 10.1161/STROKEAHA.109.561795

17. Hemphill JC, Bonovich DC, Besmertis Lavrentios, et al.: The ICH score: a simple reliable grading scale for intracerebral hemorrhage. Stroke. 2001, 32:891-897. 10.1161/01.STR.32.4.891

18. Hemphill JC, Farrant M, Neill TA Jr: Prospective validation of the ICH Score for 12-month functional outcome. Neurology. 2009, 73:1088-1094. 10.1212/WNL.0b013e3181b8b332

19. Fan JS, Chen YC, Huang HH, et al.: The association between on-scene blood pressure and early neurological deterioration in patients with spontaneous intracerebral haemorrhage. Emerg Med J. 2015, 32:239-243. 10.1136/emermed-2013-203114

20. Ohwaki K, Yano E, Nagashima H, et al.: Blood pressure management in acute intracerebral hemorrhage: relationship between elevated blood pressure and hematoma enlargement. Stroke. 2004, 35:1364-1367. 10.1161/01.STR.0000128795.38283.4b

21. Dandapani BK, Suzuki S, Kelley RE, et al.: Relation between blood pressure and outcome in intracerebral hemorrhage. Stroke. 1995, 26:21-24. 10.1161/01.STR.26.1.21

22. Anderson C, Heeley E, Huang Y, et al.: Rapid blood-pressure lowering in patients with acute intracerebral hemorrhage. N Engl J Med. 2013, 368:2355-2365. 10.1056/NEJMoa1214609 


\section{Cureus}

23. Elliott J, Smith M: The acute management of intracerebral hemorrhage: a clinical review . Anesth Analg. 2010, 110:1419-1427. 10.1213/ANE.0b013e3181d568c8 